\title{
Brittle-to-ductile transition of PLA induced by macromolecular orientation
}

\author{
S. Xu1 ${ }^{1}$,J.-F. Tahon ${ }^{1}$, I. De-Waele ${ }^{2}$, G. Stoclet ${ }^{1}$, V. Gaucher ${ }^{1 *}$ \\ ${ }^{1}$ Univ. Lille, CNRS, INRAE, Centrale Lille, UMR 8207 - UMET - Unité Matériaux et Transformations, F-59000 Lille, \\ France \\ ${ }^{2}$ Univ. Lille, CNRS, UMR 8516 - LASIR - Laboratoire de Spectrochimie Infrarouge et Raman, F-59000 Lille, France
}

Received 18 February 2020; accepted in revised form 21 April 2020

\begin{abstract}
This work deals with the influence of biaxial orientation on the mechanical behavior of Polylactide (PLA) films. Comparisons between a crystallizable grade and a non-crystallizable one have been made in order to separate the effect of macromolecular orientation from the potential influence of the crystalline phase induced during the thermomechanical treatment. While unstretched PLAs exhibited brittle behavior at room temperature, it was observed for both types of PLA the strains at break for biaxially drawn films were remarkably enhanced to values over $100 \%$. This study highlights for the first time, in the case of PLA, that a critical molecular chain orientation of the amorphous phase is the necessary condition to induce a ductile behavior. In-situ small-angle X-ray scattering (SAXS) experiments and post-mortem microscopic observations have revealed that it is a change of elementary plastic deformation mechanisms that is at the origin of this Brittle-to-Ductile (B-D) transition.
\end{abstract}

Keywords: mechanical properties, brittle-to-ductile transition, biorientation, trichroic FTIR, deformation mechanisms

\section{Introduction}

Polylactide (PLA) is one of the most promising biopolymers that actually takes part in the commercialized biopolymer market. However, its intrinsic brittleness has found to be a major limit to a wider range of applications. For the past decades, the development and optimization of different physical and chemical routes to improve the mechanical properties of PLA has been a frequently addressed topic. Various methods have been proposed, such as blending with other polymers [1-4], crosslinking to achieve superior entanglement density [5-7], incorporation of nanofillers [8-10] and processing with specific mechanical elaboration conditions [11, 12].

Regarding the application fields, one of the most commonly applied processes for the elaboration of PLAbased films or bottles is through stretching above the glass transition temperature, either uniaxially or biaxially. This process is well known as a deformation route able to improve the mechanical properties as already reported for other polymers, as poly (styrene) [13-16] and poly(ethylene terephthalate) [17-19]. Previous studies on biaxial stretching of PLA mainly focus on the structural evolution of this biopolymer upon stretching and the influence of the elaboration conditions or post-stretching treatments on the end-use properties of the biaxially oriented (BO) films, for instance, the improvement of barrier properties [20]. Ou and Cakmak [21, 22] reported in several successive studies that simultaneous biaxial stretching leads to a structure exhibiting in-plane isotropy that contains poorly ordered crystalline regions in an amorphous polymer matrix. The positive effect of biaxial stretching on crystallization kinetics of PLA was investigated by Tsai et al. [23]. It was later completed by Wu et al. [24], who studied the 
influence of biaxial stretching parameters on thermal, mechanical, and shrinkage properties of $\mathrm{BO}$ films. These authors have identified a remarkable increase of the strain at break of BO PLA up to $100 \%$. This stretchability enhancement was later studied in detail by Jariyasakoolroj et al. [25], in their work authors ascribed the impressive mechanical behavior improvement to the formation of crystalline lamellae during biaxial stretching, i.e. to the strain-induced crystallization process. Recently Razavi et al. [26] have also linked these induced 'nanocrystals' to BD transition observed with uniaxially stretched PLAs. In their study, the authors also highlighted the key role of physical aging on mechanical behavior both in the case of isotropic and stretched films. Particularly they point out that isotropic PLA undergoes fast physical aging after quenching, which leads to an embrittlement of the material.

Previous laboratory work has clearly shown that it is still quite possible to observe a brittle to ductile (B-D) transition in BO PLA that remains fully amorphous even after stretching [27]. Note that this result is in good agreement with a past study on polystyrene films [15], in which research authors have observed that while unoriented PS is extremely brittle, highly biaxially stretched films were able to strain as high as $100 \%$ during the uniaxial tensile test.

Based on the two latter studies, one may wonder if the formation of a crystalline structure is, after all, a necessary condition to induce a B-D transition. Regarding the potential influence factors, besides the straininduced crystallization process, one should also consider the role of macromolecular orientation. To address this specific point, the present study is mainly aimed at determining the origin of B-D transition that has been observed, especially in the case of PLA. PLA is synthesized from lactic acid $\left(\mathrm{C}_{3} \mathrm{H}_{6} \mathrm{O}_{2}\right)$, an enantiomeric molecule with two stereoisomers (Land D-lactide) leading to different homopolymers or random copolymer grades characterized by various $\mathrm{L} / \mathrm{D}$ isomer ratio. Typical grades used in the industry contain D-lactide as the minor unit (usually less than $10 \%)$. The possibility of varying the D-isomer content is an interesting particularity since, in this way, one can modulate the crystallization behavior of this polymer. Tábi et al. [28] demonstrated that the decrease of the D-isomer content induces a shift of the cold crystallization towards lower temperatures, which promoted the formation of $\alpha^{\prime}$ crystals. By contrast, Saeidlou et al. [29] suggested in their review that the increase of a minor unit, no matter L or D-lactide, decreases the crystallization rate, which results in a limitation of maximum achievable crystallinity. It was also pointed out that for PLAs holding higher than $10 \%$ of D content, crystallization is extremely suppressed, leading to non-crystallizable amorphous materials.

The goal of this work lies in a better understanding of the B-D transition for bi-oriented PLA films. The role of strain-induced phases, as well as the chain orientation, in the ductility improvement, will be investigated. Thus, two PLA grades, a crystallizable and a non-crystallizable one, are compared to separate the respective effects of crystalline structure and macromolecular orientation on the mechanical behavior.

\section{Experimental}

\subsection{Materials}

Pellets of PLA used in this study are purchased from NatureWorks LLC. The crystallizable grade PLA 4043D (C-PLA) and the non-crystallizable grade PLA 4060D (NC-PLA) contain roughly 2 and 8-10\% of D component, respectively. Molecular weights were determined using GPC. The number-average and weight-average molecular weights of C-PLA are $M_{\mathrm{n}}=75 \mathrm{~kg} / \mathrm{mol}$ and $M_{\mathrm{w}}=124 \mathrm{~kg} / \mathrm{mol}$ and for NC-PLA the values are $M_{\mathrm{n}}=61 \mathrm{~kg} / \mathrm{mol}$ and $M_{\mathrm{w}}=$ $104 \mathrm{~kg} / \mathrm{mol}$. Both materials were elaborated using an extrusion line type LE25-30/C at $190^{\circ} \mathrm{C}$ and cast into films on a chill-roll at room temperature resulting in isotropic amorphous films. The different crystallization ability for the two PLAs was confirmed by their thermal behavior after annealing treatment. For each grade of PLA, two film thicknesses of 100 and $500 \mu \mathrm{m}$ are prepared to fulfill different requirements of methods of characterization presented in the next sections.

\subsection{Mechanical experiments}

\subsubsection{Biaxial stretching}

A Karo IV biaxial stretcher (Brückner) was used for the biaxial drawing of the specimens. Experiments were carried out on $100 \times 100 \mathrm{~mm}^{2}$ squares cut from the extruded films. Simultaneous biaxial stretching along the machine direction (MD) and transversal direction (TD) was carried out at a drawing temperature $\left(T_{\mathrm{d}}\right)$ of $70^{\circ} \mathrm{C}$ using an initial stretching rate of $\dot{\varepsilon}=0.1 \mathrm{~s}^{-1}$. In fact, $T_{\mathrm{d}}$ is chosen above the glass transition temperature of both $\operatorname{PLAs}\left(\sim 55^{\circ} \mathrm{C}\right)$ and also before cold crystallization temperature to perform 


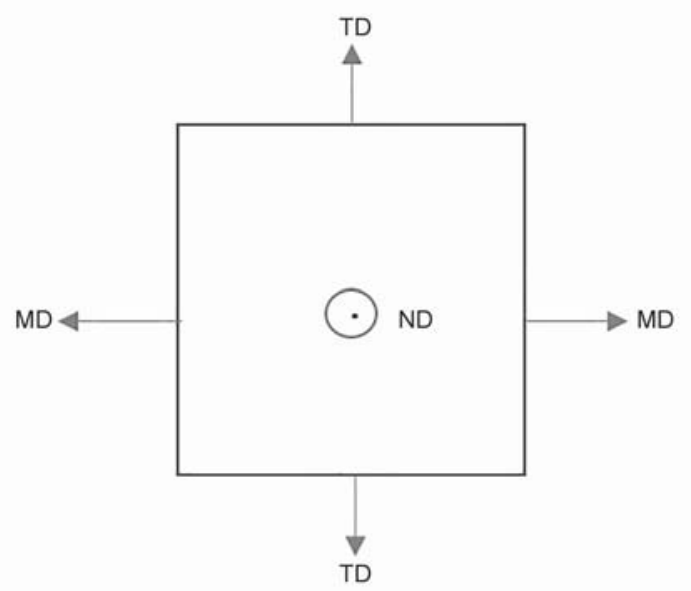

Figure 1. Schematic illustration of a film being biaxially stretched (MD is parallel to the extrusion line direction)

homogenous deformation during the stretching while avoiding thermally induced crystallization. To prevent further crystallization and to freeze the microstructure in its stretched state, the BO films were directly quenched to room temperature just at the end of biaxial stretching and then unloaded from the stretcher to be prepared for characterizations. The schematic illustration of the BO film is presented in Figure 1. Note that MD is parallel to the film extrusion direction. Before stretching the sample is pre-heated during $60 \mathrm{~s}$ at $T_{\mathrm{d}}$ to reach thermal equilibrium. Finally, draw ratios $\lambda_{\mathrm{MD}} \times \lambda_{\mathrm{TD}}$ up to $4 \times 4$ were tested $(\lambda=($ Final stretched length)/(initial length)). For each test, a same mechanical behavior was observed along MD and TD. Thus, for the sake of clarity, only the engineering stress-draw ratio recorded along MD is reported for the biaxial behavior.

It is important to note that all types of films, whether the as-cast or biaxially stretched, have undergone the same period of physical aging (at room temperature) before being characterized by each method described in the following sections. Particularly for the uniaxial tensile test (Section 2.2.2), all tests were planned to be conducted a few hours after the biaxial stretching.

\subsubsection{Uniaxial tensile test}

Uniaxial stretching was performed on an Instron 4466 apparatus Tests were carried out at room temperature using an initial stretching rate $\dot{\varepsilon}=4 \cdot 10^{-3} \mathrm{~s}^{-1}$. For each type of sample, at least five dumbbell specimens with 28 and $5 \mathrm{~mm}$ in gauge length and width respectively were tested.

\subsection{Structural characterization}

\subsubsection{Ex-situ 2D WAXS experiment}

Wide-angle X-ray scattering (WAXS) experiments were carried out owing to a Xeuss (XENOCS) SAXSWAXS equipment using the $\mathrm{Cu} K)$ radiation $(\lambda=$ $1.54 \AA$ ). The WAXS patterns were collected on a Pilatus 100k detector (Dectris). Intensity files are computed from the 2D WAXS patterns using the Foxtrot ${ }^{\circledR}$ software. Standard corrections (dark subtraction, empty beam correction and so on) were applied before performing any treatment to obtained patterns. Average diffractograms were calculated from the normalized intensity profiles recorded in the three film directions and then simulated by Peakfit ${ }^{\circledR}$ software with the value of $2 \theta$ within the range $\left(2-58^{\circ}\right)$. Assuming Gaussian distribution, the profile for as-cast, i.e. fully amorphous PLA, was deconvolved into four components with $2 \theta \approx 15.5^{\circ}, 2 \theta \approx$ $21.7^{\circ}, 2 \theta \approx 30.4^{\circ}$ and $2 \theta \approx 43.8^{\circ}$. Figure 2 shows an example of the deconvolution of cast C-PLA. For each calculation, the four representative components of the amorphous phase were fixed in terms of peak positions and full-width at half-maximum (FWHM) values.

\subsubsection{In-situ SAXS experiment}

The plastic deformation mechanisms involved during the uniaxial stretching at room temperature of the materials were assessed using in-situ SAXS experiments on the BM02 beamline at the European Synchrotron Radiation Facility (Grenoble, France). SAXS experiments were carried out using the energy of $10 \mathrm{keV}$ (i.e. $\lambda=1.26514 \AA$ ) and a sample-to-detector

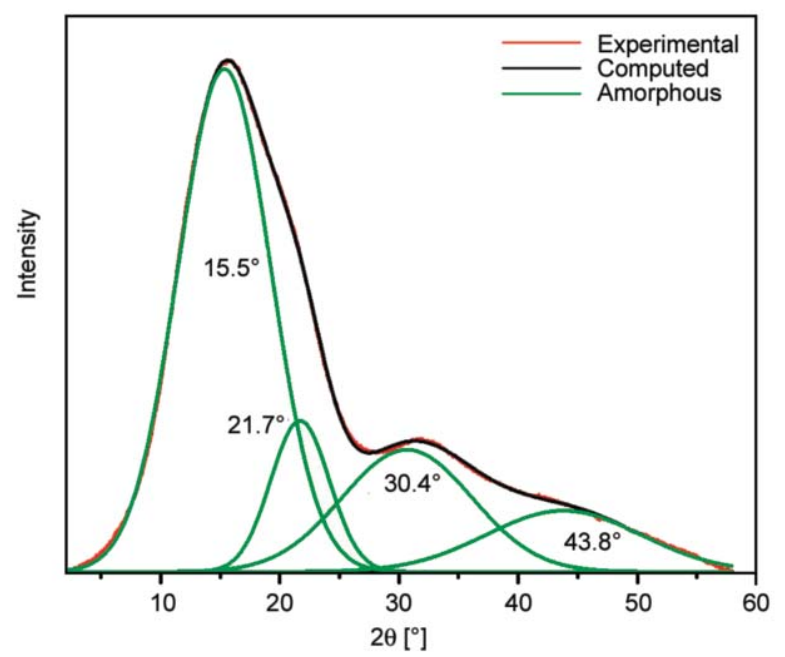

Figure 2. Example of the deconvolution profile of an as-cast C-PLA. 
distance of $1.20 \mathrm{~m}$. Mechanical tests have been performed on a portable homemade stretching device designed for symmetrical stretching and to adapt to the beamline. In-situ tensile tests were performed using the same conditions than the ones used for $e x$ situ mechanical tests, i.e. $\dot{\varepsilon}=4 \cdot 10^{-3} \mathrm{~s}^{-1}, T=23^{\circ} \mathrm{C}$.

\subsection{Molecular orientation quantification}

FTIR spectra were collected in transmission mode on a Bruker VERTEX 70v spectrometer equipped with a DTGS detector and a rotating polarizer. Every FTIR spectrum consisting of 64 scans was recorded over the wavenumber range $370-3500 \mathrm{~cm}^{-1}$ with a resolution of $2 \mathrm{~cm}^{-1}$. All collected spectra were treated with baseline corrections. In our study, trichroic infrared measurements were applied to assess the orientation functions along with the $\mathrm{M}, \mathrm{T}$, and $\mathrm{N}$ directions following the procedure described in [30-32]. For spectra along stretching axis, $S_{\mathrm{M}}$ and $S_{\mathrm{T}}$ were measured with the polarization parallel to the MD and TD, respectively, where reduced absorbance was recorded. $S_{\mathrm{N}}$ through the film was obtained by tilting the films about the $\mathrm{T}$ axis at $45^{\circ}$ with respect to the IR beam, and the spectrum $S_{\mathrm{MN}}$ was measured with the polarization in the (MN) plane. Then, the spectrum $S_{\mathrm{N}}$ corresponding to polarization through the thickness was computed from Equation (1):

$S_{\mathrm{N}}=2 n^{2} \sqrt{1-\frac{1}{2 n^{2}}} \cdot S_{\mathrm{MN}}-\left(2 n^{2}-1\right) \cdot S_{\mathrm{M}}$

where $n$ is the effective refractive index of the polymer in the direction of the beam propagation and was reported equal to 1.46 for PLA [33]. The average spectrum $S_{0}$ is then calculated from Equation (2):

$S_{0}=\frac{1}{3}\left(S_{\mathrm{M}}+S_{\mathrm{T}}+S_{\mathrm{N}}\right)$

Based on the calculated $S_{0}$ spectrum, the quantification of macromolecular orientation degree could then been performed. The orientation of a molecular chain axis $i$ is usually described by the three Herman's orientation functions $f_{\mathrm{ij}}$ where $j=\mathrm{M}, \mathrm{T}$, or $\mathrm{N}$ holds for the directions defined above. The three orientation functions must obey Equation (3):

$f_{\mathrm{iM}}+f_{\mathrm{iN}}+f_{\mathrm{iT}}=0$

If the transition moment of an infrared vibration is parallel to one of $i$ axis, Herman's orientation function can be calculated by Equation (4):
$f_{\mathrm{ij}}=\frac{1}{2}\left(\frac{A_{\mathrm{j}}}{A_{0}}-1\right)$

where $A_{\mathrm{j}}$ and $A_{0}$ are band intensities in $S_{\mathrm{j}}$ and $S_{0}$ spectrum, respectively.

For the sake of accuracy at least 5 times of measurements were carried out on BO films, and only the average orientation function values will be presented.

\subsection{Thermal properties}

Differential Scanning Calorimetry (DSC) was performed on a Perkin Elmer Q20 apparatus. Samples of about $10 \mathrm{mg}$ were placed into aluminum pans and heated at $10^{\circ} \mathrm{C} / \mathrm{min}$ within temperature range $(20$ $180^{\circ} \mathrm{C}$ ). The temperature and heat flow were calibrated using a high purity indium sample according to standard procedures. Note that the thermograms obtained for unstretched films (as-cast) were measured with films that have been thermally treated in the biaxial stretcher for the same duration as the biaxial stretching of the film of highest stretch ratio. These thermally treated unstretched samples are considered as reference samples in the thermal properties section, as shown later in this article.

\section{Results and discussions}

\subsection{Mechanical behavior during biaxial stretching}

The mechanical behavior upon biaxial stretching of C-PLA and NC-PLA cast films is presented in Figure 3. As shown in Figure 3a where engineering stress was plotted as a function of draw ratio, both materials exhibit a rubbery-material-like behavior, consisting of first of all a viscoelastic stage at low strains, then a short plateau at intermediate draw ratios followed by a strain-hardening domain at high strains before rupture. C-PLA breaks at $3.5 \times 3.5$, which is slightly lower than NC-PLA, i.e. $4 \times 4$. The observed rubbery behavior that was already reported in $[20,27]$ could be expected considering that both amorphous PLA films are stretched above their glass transition temperature, which is around $55^{\circ} \mathrm{C}$, as it shown later in this paper.

The stress level of both PLAs nearly superimposes until the onset of the strain-hardening stage. Note that the onset of strain hardening occurs earlier for C-PLA $(\lambda \times \lambda=2.5 \times 2.5)$ than for NC-PLA $(\lambda \times \lambda=$ $3 \times 3)$ and the strain hardening is more pronounced for C-PLA. The origin of the strain-hardening stage has mainly been debated in the literature, especially 

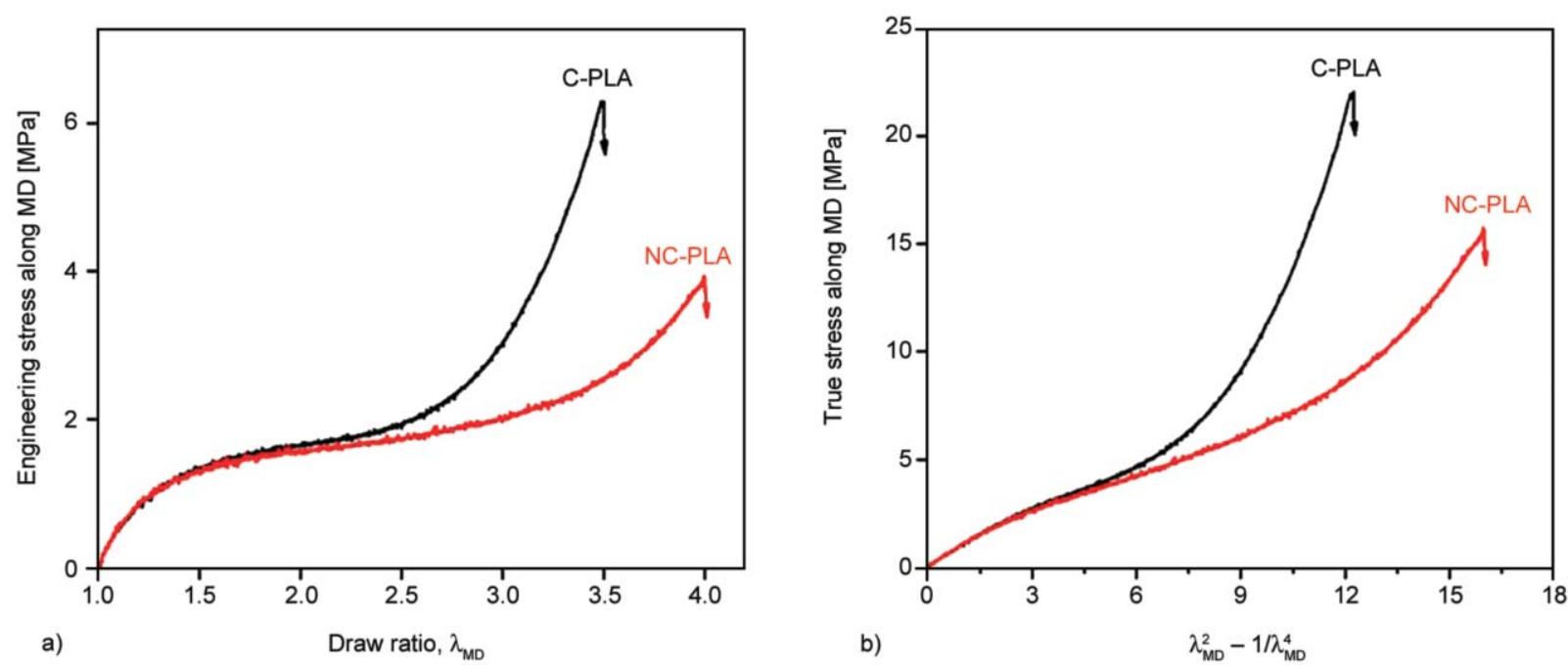

Figure 3. Biaxial stretching behavior of C-PLA and NC-PLA at $70^{\circ} \mathrm{C}$ at $\varepsilon^{\circ}=0.1 \mathrm{~s}^{-1}$ : (a) engineering stress versus draw ratio curve (b) true stress versus $\left(\lambda_{\mathrm{MD}}^{2}-1 / \lambda_{\mathrm{MD}}^{4}\right)$ curve.

in the case of uniaxial stretching. It turns out that two effects could be addressed to its origin:

1) Chain orientation due to a highly extended macromolecular network as once observed for annealed polystyrene [34].

2) The occurrence of strain-induced crystallization during stretching as reported for PET $[35,36]$.

Structural characterizations on BO films in the following sections provide some answers regarding the difference in the hardening of the two PLAs.

To further analyze the mechanical behavior during stretching, Figure $3 \mathrm{~b}$ represents this rubbery behavior according to the conventional Gaussian theory of rubber elasticity [37]: the internal true stress $\sigma_{\text {true }}$ calculated by $\sigma_{\text {true }}=\sigma_{\text {engi }} \cdot \lambda$ (isochoric deformation) can be related to the draw ratio $\lambda$ by Equation (5) in the case of biaxial tension (only MD direction is presented for the sake of clarity):

$\sigma_{\text {true }}=G\left(\lambda_{\mathrm{MD}}^{2}-\frac{1}{\lambda_{\mathrm{MD}}^{4}}\right)$

where $G$ is the shear modulus given by Equation (6):

$G=\frac{\rho R T}{M_{\mathrm{e}}}$

With $\rho$ the density of PLA equals to $1.24 \mathrm{~g} / \mathrm{cm}^{3}$ [38] and $M_{\mathrm{e}}$ the molecular weight between entanglements. The rubber network elongation no longer obeys Gaussian statistics as soon as the strain-hardening stage appears. From the Gaussian behavior regions (linear parts), the shear modulus was estimated to $0.60 \pm 0.04 \mathrm{MPa}$ resulting in a molecular entanglement weight $M_{\mathrm{e}}$ of $5800 \pm 300 \mathrm{~g} / \mathrm{mol}$, i.e. $81 \pm 5$ monomer units between entanglements for both materials. These values are close to the ones already reported in the literature [39].

\subsection{Mechanical behavior of BO films at room temperature}

The effect of biaxial stretching on the uniaxial tensile behavior of both PLA films was investigated at room temperature. Particular attention has been paid to the evolution of strain at break as a function of draw ratio, as depicted in Figure 4. It is noticed that the unstretched (isotropic) samples are very brittle, as already reported in [40]. Note that the brittle behavior is observed whatever the film thickness in the range of $50-500 \mu \mathrm{m}$, as long as the film is in isotropic state. By contrast, a ductile behavior is observed

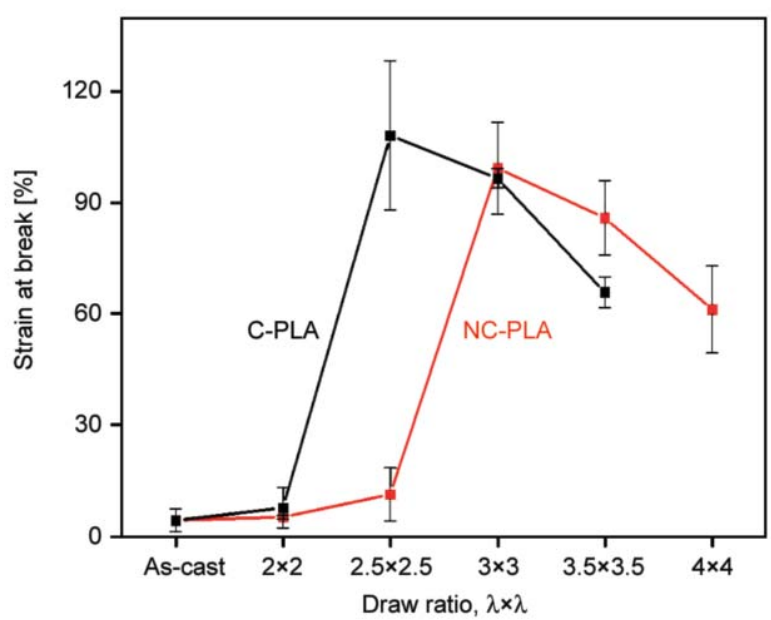

Figure 4. Strain at break as a function of draw ratios of as cast and BO films of two grades uniaxially drawn at $\dot{\varepsilon}=4 \cdot 10^{-3} \mathrm{~s}^{-1}, 70^{\circ} \mathrm{C}$. 
for the C-PLA samples as soon as the biaxial draw ratio is above $2 \times 2$. A similar evolution is observed for NC-PLA except that the transition occurs for a slightly higher critical draw ratio, i.e. $2.5 \times 2.5$. These results confirm the thermomechanically induced B-D transition in both PLAs.

Besides, this gain in terms of strain at break reaches an optimum value of over $100 \%$ for C-PLA stretched at $2.5 \times 2.5$ and for NC-PLA stretched at $3 \times 3$. These optimum ratios correspond to the onset ratio of strain -hardening previously determined on biaxial stretching behavior. As soon as the most optimized ratios are attained, the strain at break values steadily decreases with the increase of the biaxial draw ratio. It can be explained by the fact that at high stretch ratio, molecular chains are extremely oriented and consequently near to their limit of extension so that the aptitude to deform during the uniaxial test should be less significant. The improvement of ductility through biaxial stretching is further interpreted with complementary structural characterizations.

\subsection{Thermal properties determined by DSC}

The thermal behavior of unstretched (as described in section 2.5) and biaxially stretched PLAs at different draw ratios is illustrated in Figure 5. The glass transition temperatures for cast C-PLA and NC-PLA are determined at about 55 and $53^{\circ} \mathrm{C}$, respectively.

This figure shows that the two grades of PLA exhibit different behaviors:

For C-PLAs, with the increase of draw ratio, the crystallization temperature decreases slowly and gradually while the area of the exothermic peak steadily increases, as shown in Figure 5a. This observation can be attributed to the increase of the macromolecular orientation degree, which favors the crystallization of PLA. A similar beneficial effect of orientation on crystallization behavior has been reported for uniaxially stretched PET films [41-43]. Nevertheless, it can be concluded from Table 1 that no strain-induced crystals are presented in the oriented films since the difference of enthalpy $\Delta H_{\mathrm{m}}-\Delta H_{\mathrm{cc}}$ is negligible. In addition to cold crystallization, an endotherm occurs immediately after the glass transition around 65$70^{\circ} \mathrm{C}$, which is ascribed to the signature of the melting of an intermediate mesomorphic phase formed upon stretching [44]. The peak intensity steadily increases with the draw ratio and then completely merges with the glass transition for samples stretched at $\lambda \times \lambda \geq 2.5 \times 2.5$, i.e. up to the onset value of strainhardening stage of mechanical behavior during biaxial stretching as previously discussed. This increase of strain-induced 'ordered' phase content should be taken into account as a parameter contributing to the hardening process.

For NC-PLA samples, neither crystallization nor melting was observed upon heating, as illustrated by Figure 5b. Nevertheless, a similar endothermic peak near the glass transition temperature is detectable for a stretch ratio higher than $3 \times 3$; afterward, the area of peak seems to remain unchanged. Such particular thermal behavior suggests that even for PLAs unable to crystallize, it is still possible for macromolecular chains to orient upon stretching, leading to

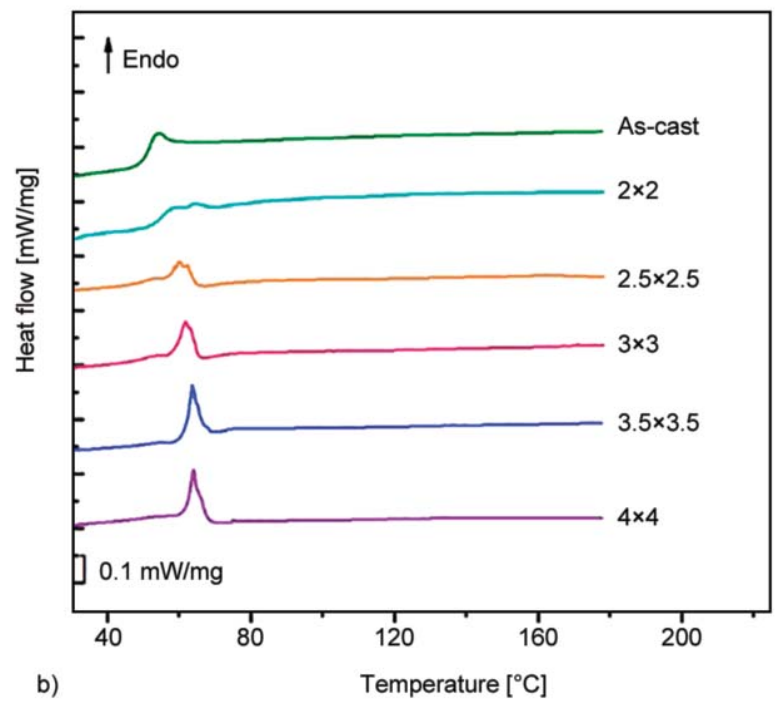

Figure 5. DSC thermograms of reference as-cast and BO samples drawn at various draw ratios at $70^{\circ} \mathrm{C}$ of (a) C-PLA (b) NC-PLA. 
the formation of mesophase when a critical stretch ratio is reached. Lee et al. [45] also pointed out similar thermal behavior for a PLA containing $10 \%$ of $\mathrm{D}$-isomer that has been uniaxially stretched at various ratios.

The percentage of the mesomorphic phase was estimated from the area of post- $T_{\mathrm{g}}$ endothermic peak using Equation (7):

$$
X_{\text {meso }}=\frac{\Delta H_{\text {meso }}}{\Delta H_{\text {meso }}^{0}}
$$

where $\Delta H_{\text {meso }}$ is the area of post- $T_{\mathrm{g}}$ endothermic peak and $\Delta H_{\text {meso }}^{0}$ refers to the specific melting enthalpy of mesophase with a value equals to $70 \mathrm{~J} / \mathrm{g}$ reported in [44]. The results are summarized in Table 1.

It seems that C-PLA tends to form more mesophase than NC-PLA when biaxially stretched, though the weight fraction of this phase remains relatively low for both types of BO PLAs. Considering the fact that the melting peak of the mesophase is superimposed with glass transition, the quantification of mesophase from DSC results should be taken with caution. In that case, the quantification of the mesophase portion is monitored through 2D WAXS experiments, and the results are reported in the next section.

\subsection{Structural characterization by WAXS}

To analyze the structure and to determine the composition of BO films, ex-situ WAXS measurements were carried out in both in-plane (MT) and profile (MN, TN) configurations. 2D WAXS patterns and the average intensity profiles computed from these patterns are depicted in Figure 6.

For each type of PLA, the MT, MN, and TN patterns shown in Figure $6 \mathrm{a}$ and $6 \mathrm{~b}$ of the non-oriented films exhibit a broad uniform halo indicating the isotropic and amorphous nature of initial samples. For bioriented samples, the broad, amorphous halo on MT patterns transforms into a diffuse ring for both materials indicating that samples are still isotropic in the plane.

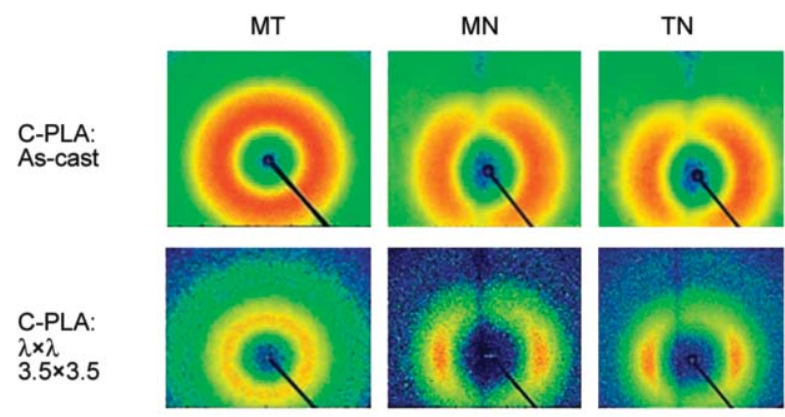

a)

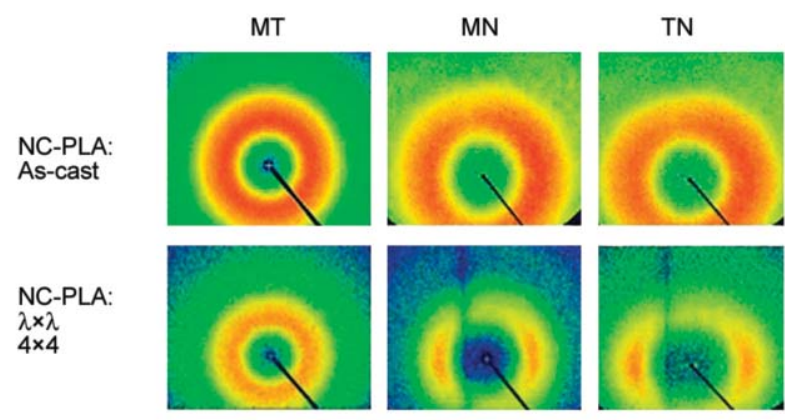

b)

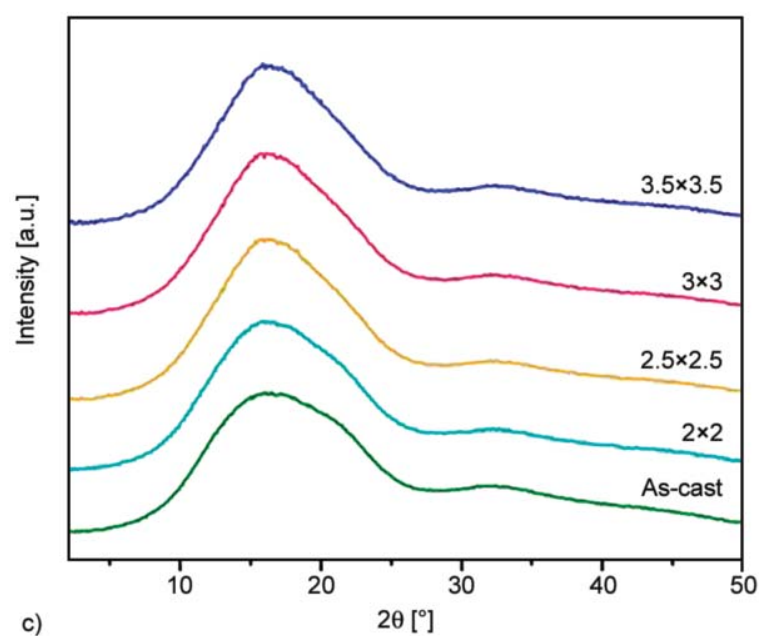

c)

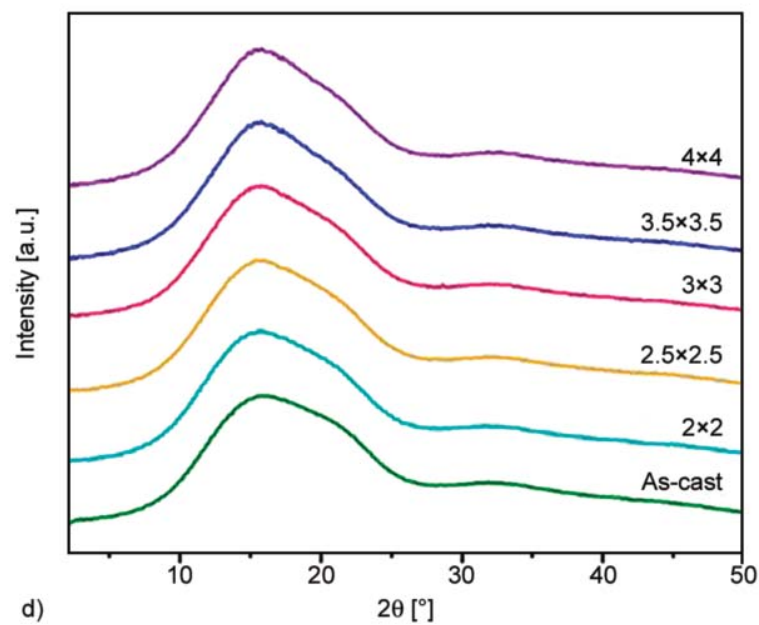

Figure 6. In-plane and profile WAXS patterns of (a) as-cast; C-PLA stretched at $3.5 \times 3.5$ (b) as-cast; NC-PLA stretched at $4 \times 4$ and average diffractograms of as-cast and BO films drawn at various ratios of (c) C-PLA (d) NC-PLA. 
Table 1. Thermal characteristic values determined for biaxially stretched C-PLA and NC-PLA at various ratios at $70^{\circ} \mathrm{C}$.

\begin{tabular}{|c|c|c|c|}
\hline \multirow{2}{*}{$\lambda_{\mathbf{M D}} \times \lambda_{\mathbf{T D}}$} & $\begin{array}{c}\Delta \boldsymbol{H}_{\mathbf{m}}-\Delta \boldsymbol{H}_{\mathbf{c c}} \\
{[\mathbf{J} / \mathbf{g} \pm \mathbf{2}]}\end{array}$ & \multicolumn{2}{|c|}{$\begin{array}{c}\boldsymbol{X}_{\text {meso }} \\
{[\mathbf{\%} \pm \mathbf{1}]}\end{array}$} \\
\cline { 2 - 4 } & $\mathbf{C - P L A}$ & $\mathbf{C}-P L A$ & NC-PLA \\
\hline $2 \times 2$ & 0 & 2 & 0 \\
\hline $2.5 \times 2.5$ & 0 & 4 & 1 \\
\hline $3 \times 3$ & 1 & 6 & 2 \\
\hline $3.5 \times 3.5$ & 1 & 8 & 4 \\
\hline $4 \times 4$ & $\mathrm{ND}$ & $\mathrm{ND}$ & 4 \\
\hline
\end{tabular}

By contrast, a pair of equatorial arcs are detected on the profile patterns revealing chain orientation along the stretching axis in the film plane without a sign of strain-induced crystallization as no clear diffraction spots were ever detected. Although biaxial stretching plays an active role in facilitating crystallization, the efficiency to crystallize still appears less significant than in the case of uni- oriented PLA as manifested by Oh et al. [46] in their study of a crystallizable grade. Ou and Cakmak [21] suggested that simultaneous biaxial stretching tends to orient polymer chains in a random direction in-plane, causing difficulties to crystallize with chains along the same direction.

Regarding the average diffractograms in Figure $6 c$ and $6 \mathrm{~d}$, the absence of distinct sharp peaks proves once again the lack of well-defined three-dimensional crystalline order in the biaxially stretched films. Yet the presence of a second phase apart from amorphous has been clearly revealed by the emergence of two new peaks around $2 \theta \approx 16.2^{\circ}$ and $2 \theta \approx 32.8^{\circ}$ when deconvolving profiles of $\mathrm{BO}$ samples, as can be seen in Figure 7. These new peaks should be attributed to the formation of mesophase $[44,46]$.

MT WAXS pattern indicates that this mesophase is randomly dispersed in the film plane; however, in profile directions, a preferential order of distribution along the stretching axis should be considered, as schematically presented in Figure 8 and is confirmed by FTIR experiments in the next section.

The quantification of mesophase content is summarized in Table 2. It was found that the calculated percentage is close to what has been determined from DSC thermograms. The difference of the mesophase portion of the two PLAs should contribute to the different hardening behavior formerly discussed since C-PLA presents a higher strain-hardening slope than the NC-PLA, for whom the quantity is

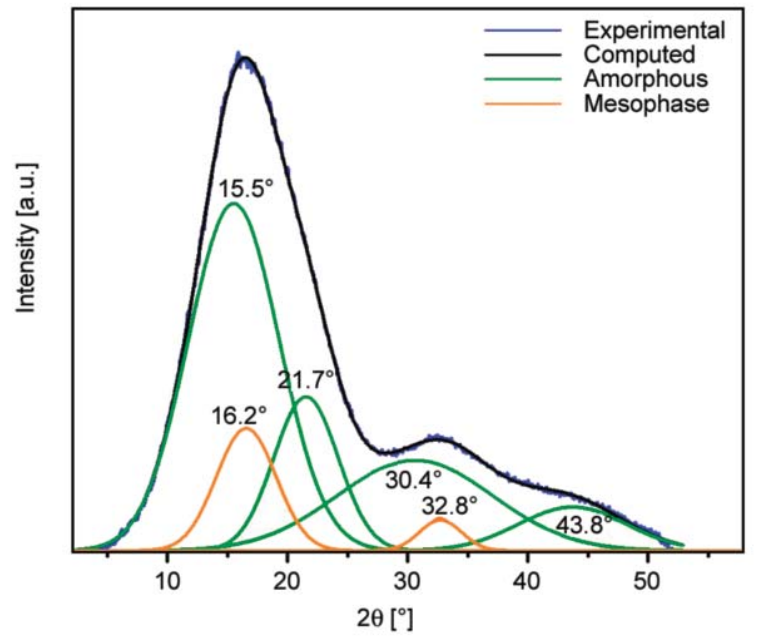

Figure 7. The deconvolution profile of a C-PLA biaxially stretched at $3.5 \times 3.5$ at $70^{\circ} \mathrm{C}$.
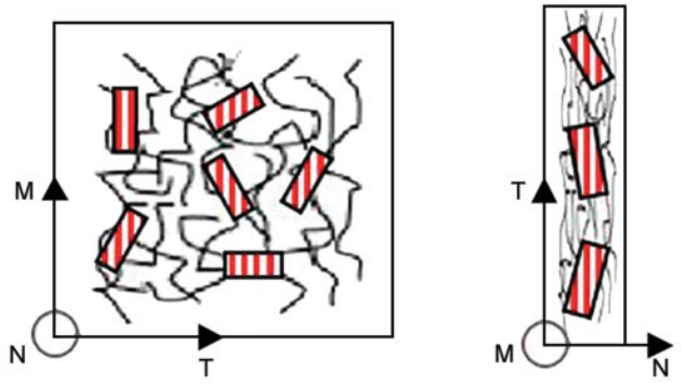

Mesophase

Figure 8. Schematic representation of the distribution of mesophase in BO PLA films.

Table 2. Mesophase content quantified by Peakfit ${ }^{\circledR}$ software for C-PLA and NC-PLA.

\begin{tabular}{|c|c|c|}
\hline \multirow{2}{*}{$\boldsymbol{\lambda}_{\mathbf{M D}} \times \boldsymbol{\lambda}_{\mathbf{T D}}$} & \multicolumn{2}{|c|}{$\boldsymbol{X}_{\mathbf{m e s o}}[\mathbf{\%} \pm \mathbf{2}]$} \\
\hline 2 & $\mathbf{C}-\mathbf{P L A}$ & $\mathbf{N C - P L A}$ \\
\hline $2 \times 2$ & 2 & 0 \\
\hline $2.5 \times 2.5$ & 3 & 0 \\
\hline $3 \times 3$ & 5 & 1 \\
\hline $3.5 \times 3.5$ & 7 & 1 \\
\hline $4 \times 4$ & $\mathrm{ND}$ & 2 \\
\hline
\end{tabular}

barely traceable even at high stretch ratios. More importantly, considering the low content of induced mesophase, one could suggest that it is the molecular orientation which mainly governs the hardening process for both PLAs.

2D WAXS results confirmed that the strain-induced mesophase remains in low quantity for both materials. Therefore the presence of induced 'ordered' phase is not taken into account of influence factors on the mechanical properties of $\mathrm{BO}$ samples that is later discussed in this paper. 


\subsection{Orientation quantification by FTIR}

2D WAXS results allow us to characterize the 'ordered' structure involved and to assess the amorphous macromolecular orientation in $\mathrm{BO}$ films qualitatively. To complete the characterization of the amorphous phase, trichroic FTIR analysis was performed to obtain the chain orientation functions along the three mutually orthogonal axes of the film: $\mathrm{M}, \mathrm{N}$, and $\mathrm{T}$ directions. According to several spectroscopic pieces of research of PLA, the characteristic bands detected at 956 and at $918 \mathrm{~cm}^{-1}$ are ascribed to the amorphous phase and mesophase, respectively [47-49].

The spectra obtained along three axes for BO films are presented in Figure 9. First of all, the emergence of the band at $918 \mathrm{~cm}^{-1}$ confirms once again the presence of mesophase [44, 47-49]. The superposition of $S_{\mathrm{M}}$ and $S_{\mathrm{T}}$ spectrum shows clearly that the film is equally oriented along the $\mathrm{M}$ and $\mathrm{T}$ directions, while the $S_{\mathrm{N}}$ spectrum exhibits a decrease of band at $956 \mathrm{~cm}^{-1}$ combined with the increase of band at $918 \mathrm{~cm}^{-1}$, for instance, as illustrated in Figure 9a for BO C-PLA. This observation of the trichroic behavior of amorphous and mesomorphic phases suggests that the stretched film is textured with a planar orientation in both phases. It is also noticed that the absorbance of the band at $918 \mathrm{~cm}^{-1}$ is extremely low and barely oriented especially in the case of NC-PLA (Figure 9b), which is in agreement with previous WAXS analysis.

The orientation functions of the chain axis in the amorphous phase are summarized in Table 3. For the sake of clarity, only selected orientation functions are represented in the Wilchinski diagram (Figure 10). All measured points are located upon the median of the MT plane confirming that the polymer chain axis is equally oriented along the $\mathrm{M}$ and $\mathrm{T}$ directions. As expected, for both PLAs the evolution tendency of orientation functions indicates that the chain axis progressively orients towards MT plane with the increase of draw ratios. Note that at the same draw ratio, the orientation functions are slightly different between the two materials with a particularly higher value obtained for C-PLA.

This faster orientation kinetics observed for C-PLA could be ascribed to a higher presence, even though low, of induced mesophase content. Indeed, the mesomorphic domain can be considered as physical entanglement points that promote chain orientation by restricting molecular mobility. In addition, thermal

Table 3. Orientation functions of chain axis of amorphous phase obtained from the trichroic spectra with band at $956 \mathrm{~cm}^{-1}$.

\begin{tabular}{|c|c|c|c|c|c|c|c|}
\hline & \multicolumn{6}{|c|}{ Chain orientation functions of amorphous phase } \\
\cline { 2 - 9 } & \multicolumn{3}{|c|}{ C-PLA } & \multicolumn{5}{c|}{ NC-PLA } \\
\hline$\lambda \times \boldsymbol{\lambda}$ & $\boldsymbol{f}_{\text {cM }}$ & $\boldsymbol{f}_{\text {cT }}$ & $\boldsymbol{f}_{\mathbf{c N}}$ & $\boldsymbol{\lambda} \times \boldsymbol{\lambda}$ & $\boldsymbol{f}_{\text {cM }}$ & $\boldsymbol{f}_{\mathbf{c T}}$ & $\boldsymbol{f}_{\mathbf{c N}}$ \\
\hline $2 \times 2$ & 0.069 & 0.067 & -0.137 & $2 \times 2$ & 0.055 & 0.059 & -0.115 \\
\hline $2.5 \times 2.5$ & 0.085 & 0.087 & -0.178 & $2.5 \times 2.5$ & 0.072 & 0.071 & -0.142 \\
\hline $3 \times 3$ & 0.106 & 0.108 & -0.215 & $3 \times 3$ & 0.081 & 0.082 & -0.163 \\
\hline $3.5 \times 3.5$ & 0.128 & 0.131 & -0.261 & $3.5 \times 3.5$ & 0.107 & 0.101 & -0.207 \\
\hline & & & & $4 \times 4$ & 0.121 & 0.118 & -0.237 \\
\hline
\end{tabular}

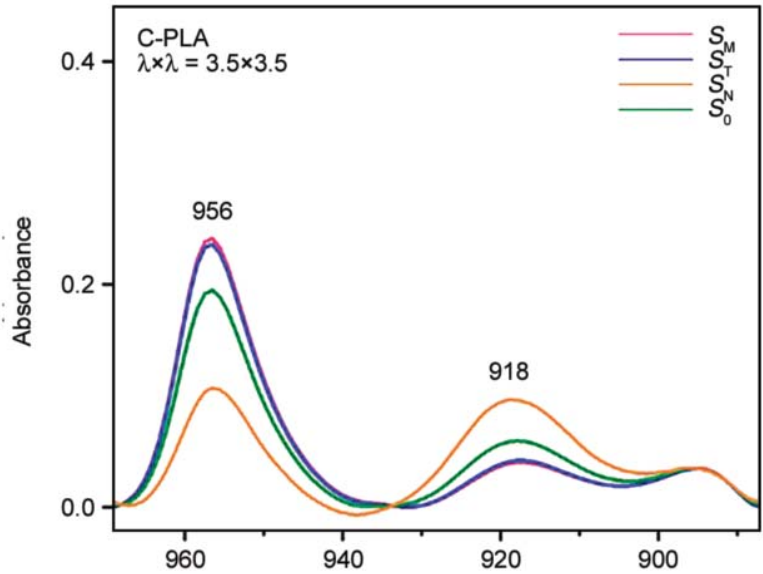

a)

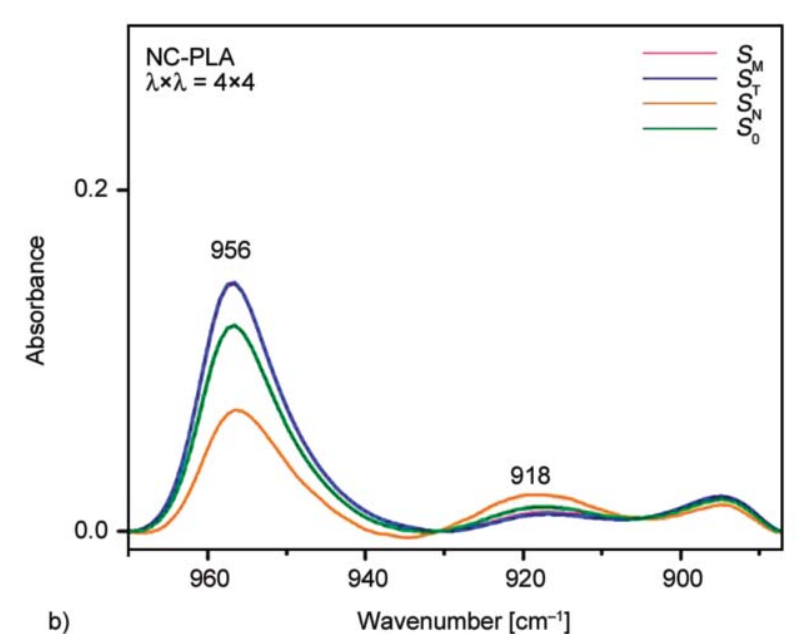

b)

Figure 9. Trichroic spectra obtained for (a) C-PLA stretched at $3.5 \times 3.5$ and (b) NC-PLA stretched at $4 \times 4$. 


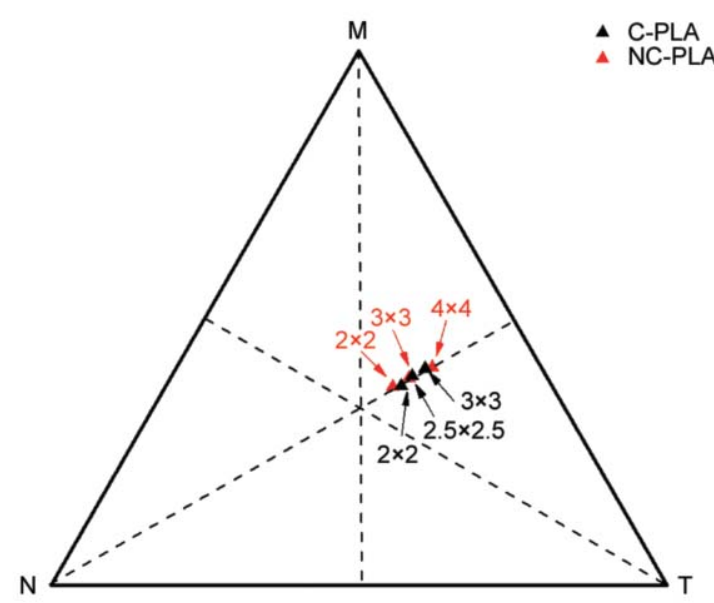

Figure 10. Wilchinski diagram of the $f_{\mathrm{ij}}$ orientation functions of the $\mathrm{c}$ axis in the amorphous phase as a function of biaxial draw ratios $\left(\lambda_{\mathrm{MD}} \times \lambda_{\mathrm{TD}}\right)$ for C-PLA and NC-PLA.

characterization indicates that the glass transition temperature of NC-PLA is $2{ }^{\circ} \mathrm{C}$ lower than the one of C-PLA. Consequently, as both polymers are stretched at the same temperature, macromolecules of NC-PLA can be expected to relax slightly faster, which may explain the observed slower orientation kinetics.

\subsection{Orientation-mechanical properties correlation study}

As formerly discussed, the B-D transition occurs at different draw ratios depending on the PLA grade. Thanks to trichroic FTIR analysis, a correlation study is now available between the onset of this transition and the macromolecular orientation. The evolution of the strain at break as a function of the orientation function of the amorphous phase has been computed and only the results of correlation with $f_{\mathrm{cM}}$ were presented in Figure 11 for the sake of clarity.

Contrary to the results presented in Figure 4 where the transition from a brittle to a ductile behavior was observed at different stretch ratios for C-PLA and NC-PLA, it appears in Figure 11 that the B-D transition occurs nearly at the same macromolecular orientation degree, i.e. $f_{\mathrm{cM}} \approx 0.07$. In addition it is observed that the highest strain at break for both PLAs is obtained for $f_{\mathrm{cM}} \approx 0.09$. Note that Choi et al. [15] obtained quite similar results when studying $\mathrm{BO}$ polystyrene with $f_{\mathrm{cM}} \approx 0.09$ ( \pm 0.04$)$ determined as optimal orientation factor for a sample strained as much as $100 \%$. This result suggests that the achievement of a critical value of chain orientation in the amorphous phase is the key parameter triggering the B-D transition. The role of mesophase quantity in

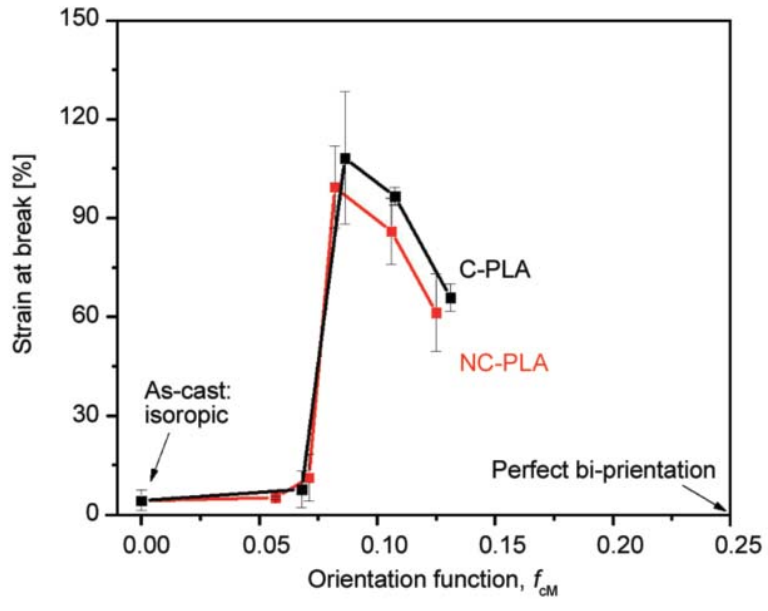

Figure 11. Correlation results of strain at break with respect to chain orientation function $f_{\mathrm{cM}}$ of amorphous phase for C-PLA and NC-PLA.

the contribution of inducing the enhancement of ductility remains unessential.

\subsection{Deformation mechanism evaluation}

In order to go further into the understanding of the origin of the brittle-ductile transition, in-situ SAXS analysis was carried out to identify the elementary plastic deformation mechanisms involved in isotropic and oriented PLAs upon uniaxial stretching. It is well known that amorphous polymers show two main localized plastic deformation mechanisms: crazes and shear bands. Crazes are microcracks that remain bridged by fibrils, which are perpendicular to the stress direction. Shear bands are found at an angle of about $50^{\circ}$ to the stress direction, and conversely to crazing, deformation by shear bands does not imply volume change. It is widely accepted that brittle polymers tend to deform preferentially by crazing whereas ductile polymers deform rather by shear banding or by homogeneous deformation bands. Figure 12 reported the SAXS patterns recorded before sample rupture of an as-cast C-PLA and a typical pattern obtained during the entire uniaxial stretching of a C-PLA biaxially stretched.

For as-cast samples, SAXS pattern consists of parallel and perpendicular streaks to drawing axis representing scattering from craze/polymer walls and craze fibrils, respectively. Such a characteristic image is considered as a signature of the crazing mechanism. On the contrary, for a typical biaxially stretched ductile sample whose orientation function is beyond the onset of critical orientation factor, only isotropic diffraction rings are detected. These observations suggest that the crazing mechanism is inhibited during 


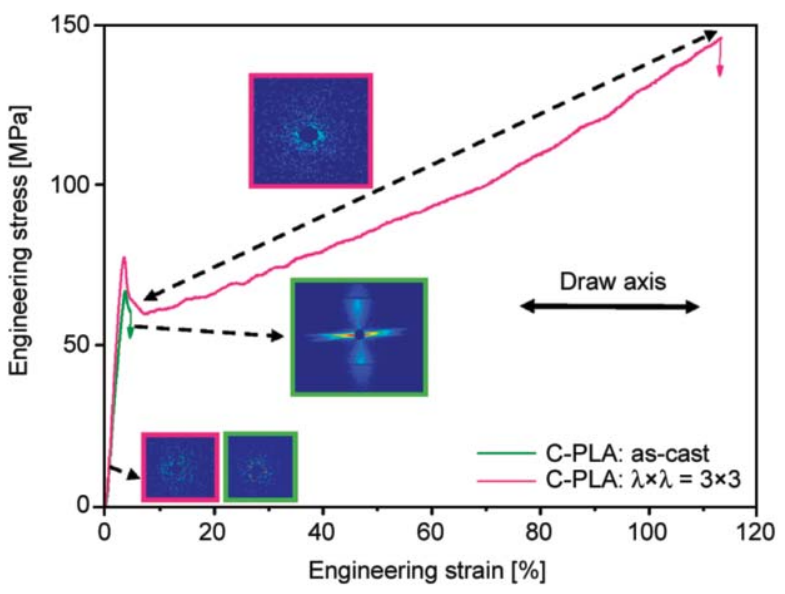

Figure 12. In-situ SAXS patterns recorded before sample break of as-cast C-PLA and a typical pattern obtained during the entire uniaxial stretching of a C-PLA biaxially stretched at $3 \times 3$.

the uniaxial deformation of BO PLA, which is in good agreement with the previous work of the laboratory [27].

To better understand the deformation mechanism performed by samples enduring ductile behavior, morphology observations have been carried out through optical microscopy, and a typical image is obtained as illustrated in Figure 13 where intersecting bands inclining approximately at $35^{\circ}$ about draw axis dominate the deformation mode known as characteristics of shear banding mechanism. Thereby we can link the origin of B-D transition to a change of deformation mechanism from crazing to shear banding. The accordance of post-mortem morphology observation with in-situ SAXS characterization results allows the following conclusion: with the increasing of molecular orientation the initial mode of deformation, i.e. crazing, could be completely suppressed in order to make way for the activation of shear banding, the more favorable deformation mechanism

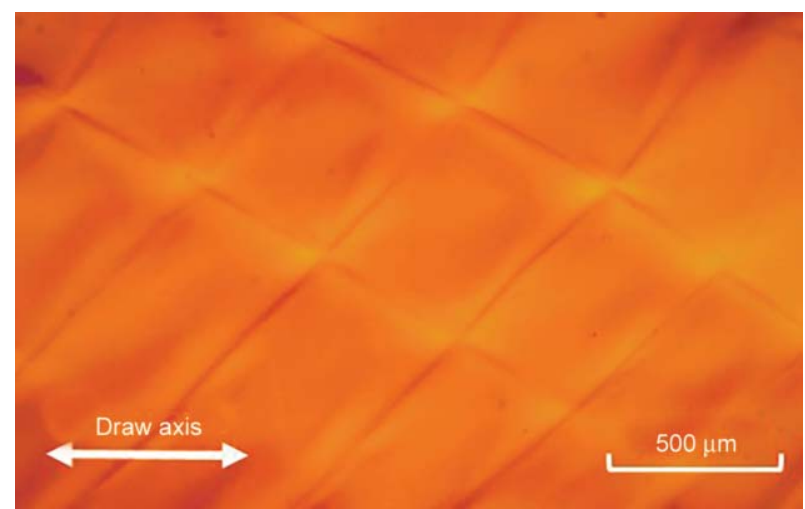

Figure 13. Optical microscopy image showing shear bands obtained for a post-mortem ductile BO PLA. at such molecular orientation state. This behavior will eventually lead to the considerable improvement of ductility of our polymer. In other words, the transition of mechanical properties is in fact the switch of one deformation mechanism to the other whenever the critical orientation level is satisfied.

\section{Conclusions}

In this work biaxially stretched PLA samples of various orientation states are characterized in terms of mechanical behavior, thermal properties, structural evolution, as well as macromolecular orientation.

Both grades of PLA revealed a remarkable brittleto-ductile transition behavior with a significant enhancement of strain at break over 100\% for BO films stretched at most favorable ratios. Two parameters were considered as possible factors triggering the B-D transition: macromolecular chain orientation and the presence of mesophase induced during the biaxial stretching.

To find out the most important parameter that triggers the transition, structural characterizations and phase quantification of post-stretched BO PLA samples have been achieved through WAXS and trichroic FTIR measurements.

The mesophase is induced at low contents for both grades of PLA as illustrated by the quantification results (overall maximum mesophase content less than $10 \%$ ). In addition, as a key point, the appearance or the quantity of such phase is not at all critical elements to induce a B-D transition. As shown in the case of NC-PLA, a sample pre-stretched at $3 \times 3$ was still able to deform as much as $100 \%$ upon tensile test while containing hardly any mesophase. Consequently this induced phase is not a required condition to obtain ductile mechanical behavior.

Concerning the role of orientation function, contrary to the previous conclusion drawn about the mesophase effect, a clear correlation between on one hand the orientation factor of the amorphous phase and, on the other hand, the strain-at-break value can be well established from the comparative study results of the two grades of PLA. Particularly it has been clearly highlighted that the achievement of a critical chain orientation is the main key parameter inducing a ductile mechanical behavior. This critical function to induce the B-D transition is determined at $f_{\mathrm{cM}}=$ $f_{\mathrm{cT}} \approx 0.07$ for both types of PLAs. Besides, an optimum value of $f_{\mathrm{cM}}=f_{\mathrm{cT}} \approx 0.09$ gives access to the higher improvement of ductility. 
Finally, in-situ SAXS investigation has revealed that the B-D transition is closely associated with a change of involved plastic deformation mechanisms. Indeed, typical crazing mechanism that occurs for brittle samples is entirely inhibited in the case of the ductile BO materials. Complementary morphological observation also confirms this change from crazing to shear banding as the explanation to the B-D transition.

As for perspectives, further investigations are under progress to better understand in which way macromolecular orientation involves in the plastic deformation mechanism transition. Moreover the effect of physical aging on the mechanical properties of BO samples is also envisaged to be studied in future work.

\section{Acknowledgements}

The authors are indebted to the ESRF Synchrotron Facility (Grenoble, France) for beam time allocation on the BM02 beamline. The authors are also indebted University of Lille and Région Haut-de-France for funding the $\mathrm{PhD}$ thesis. Financial support from Région Nord Pas-de-Calais and European FEDER for both biaxial stretching and SAXS laboratory equipment is also gratefully acknowledged. Authors also acknowledge F. Delaunay and F. Auvray for their help for film elaboration.

This manuscript is a tribute to the 50 year anniversary of the French Polymer Group (Groupe Français des Polymères GFP).

\section{References}

[1] Liu H., Zhang J.: Research progress in toughening modification of poly(lactic acid). Journal of Polymer Science Part B: Polymer Physics, 49, 1051-1083 (2011). https://doi.org/10.1002/polb.22283

[2] Joziasse C. A. P., Topp M. D. C., Veenstra H., Grijpma D. W., Pennings A. J.: Supertough poly(lactide)s. Polymer Bulletin, 33, 599-605 (1994).

https://doi.org/10.1007/BF00296170

[3] Petchwattana N., Covavisaruch S., Euapanthasate N.: Utilization of ultrafine acrylate rubber particles as a toughening agent for poly(lactic acid). Materials Science and Engineering A, 532, 64-70 (2012).

https://doi.org/10.1016/j.msea.2011.10.063

[4] Petchwattana N., Covavisaruch S., Euapanthasate N.: Mechanical and thermal behaviors of the acrylic based core-shell rubber modified poly(lactic acid). Advanced Materials Research, 306, 340-343 (2011).

https://doi.org/10.4028/www.scientific.net/AMR.306-307.340

[5] Mitomo H., Kaneda A., Quynh T. M., Nagasawa N., Yoshii F.: Improvement of heat stability of poly(L-lactic acid) by radiation-induced crosslinking. Polymer, 46, 4695-4703 (2005).

https://doi.org/10.1016/j.polymer.2005.03.088
[6] Nijenhuis A. J., Grijpma D. W., Pennings A. J.: Crosslinked poly(L-lactide) and poly( $\varepsilon$-caprolactone). Polymer, 37, 2783-2791 (1996).

https://doi.org/10.1016/0032-3861(96)87642-7

[7] Suhartini M., Mitomo H., Nagasawa N., Yoshii F., Kume T.: Radiation crosslinking of poly(butylene succinate) in the presence of low concentrations of trimethallyl isocyanurate and its properties. Journal of Applied Polymer Science, 88, 2238-2246 (2003).

https://doi.org/10.1002/app.11944

[8] Wang Y., Mei Y., Wang Q., Wei W., Huang F., Li Y., Li J., Zhou Z.: Improved fracture toughness and ductility of PLA composites by incorporating a small amount of surface-modified helical carbon nanotubes. Composites Part B: Engineering, 162, 54-61 (2019).

https://doi.org/10.1016/j.compositesb.2018.10.060

[9] Batakliev T., Georgiev V., Ivanov E., Kotsilkova R., Di Maio R., Silvestre C., Cimmino S.: Nanoindentation analysis of 3D printed poly(lactic acid)-based composites reinforced with graphene and multiwall carbon nanotubes. Journal of Applied Polymer Science, 136, 47260/1-47260/5 (2019).

https://doi.org/10.1002/app.47260

[10] Okubo K., Fujii T., Thostenson E. T.: Multi-scale hybrid biocomposite: Processing and mechanical characterization of bamboo fiber reinforced PLA with microfibrillated cellulose. Composites Part A: Applied Science and Manufacturing, 40, 469-475 (2009).

https://doi.org/10.1016/j.compositesa.2009.01.012

[11] Jonoobi M., Harun J., Mathew A. P., Oksman K.: Mechanical properties of cellulose nanofiber (CNF) reinforced polylactic acid (PLA) prepared by twin screw extrusion. Composites Science and Technology, 70, 1742-1747 (2010).

https://doi.org/10.1016/j.compscitech.2010.07.005

[12] Chacón J. M., Caminero M. A., García-Plaza E., Núñez P. J.: Additive manufacturing of PLA structures using fused deposition modelling: Effect of process parameters on mechanical properties and their optimal selection. Materials and Design, 124, 143-157 (2017). https://doi.org/10.1016/j.matdes.2017.03.065

[13] Matsumoto K., Fellers J. F., White J. L.: Uniaxial and biaxial orientation development and mechanical properties of polystyrene films. Journal of Applied Polymer Science, 26, 85-96 (1981). https://doi.org/10.1002/app.1981.070260108

[14] Zhang X., Ajji A.: Biaxial orientation behavior of polystyrene: Orientation and properties. Journal of Applied Polymer Science, 89, 487-496 (2003). https://doi.org/10.1002/app.12268

[15] Choi K-J., Spruiell J. E., White J. L.: Structure development in biaxially stretched polystyrene film: Part I. Property-orientation correlation. Polymer Engineering and Science, 29, 1516-1523 (1989). https://doi.org/10.1002/pen.760292105 
[16] Liu J., Zhao Z., Wang W., Mays J. W., Wang S-Q.: Brittle-ductile transition in uniaxial compression of polymer glasses. Journal of Polymer Science Part B: Polymer Physics, 57, 758-770 (2019).

https://doi.org/10.1002/polb.24830

[17] Maruhashi Y., Asada T.: Structure and properties of biaxially stretched poly(ethylene terephthalate) sheets. Polymer Engineering and Science, 36, 483-494 (1996). https://doi.org/10.1002/pen.10434

[18] Chandran P., Jabarin S.: Biaxial orientation of poly(ethylene terephthalate). Part I: Nature of the stress-strain curves. Advances in Polymer Technology: Journal of the Polymer Processing Institute, 12, 119-132 (1993). https://doi.org/10.1002/adv.1993.060120202

[19] Bonnebat C., Roullet G., de Vries A. J.: Biaxially oriented poly(ethylene terephthalate) bottles: Effects of resin molecular weight on parison stretching behavior. Polymer Engineering and Science, 21, 189-195 (1981). https://doi.org/10.1002/pen.760210403

[20] Delpouve N., Stoclet G., Saiter A., Dargent E., Marais S.: Water barrier properties in biaxially drawn poly(lactic acid) films. The Journal of Physical Chemistry B, 116, 4615-4625 (2012). https://doi.org/10.1021/jp211670g

[21] Ou X., Cakmak M.: Influence of biaxial stretching mode on the crystalline texture in polylactic acid films. Polymer, 49, 5344-5352 (2008).

https://doi.org/10.1016/j.polymer.2008.09.053

[22] Ou X., Cakmak M.: Comparative study on development of structural hierarchy in constrained annealed simultaneous and sequential biaxially stretched polylactic acid films. Polymer, 51, 783-792 (2010).

https://doi.org/10.1016/j.polymer.2009.11.058

[23] Tsai C-C., Wu R-J., Cheng H-Y., Li S-C., Siao Y-Y., Kong D-C., Jang G-W.: Crystallinity and dimensional stability of biaxial oriented poly(lactic acid) films. Polymer Degradation and Stability, 95, 1292-1298 (2010). https://doi.org/10.1016/j.polymdegradstab.2010.02.032

[24] Wu J-H., Yen M-S., Wu C-P., Li C-H., Kuo M-C.: Effect of biaxial stretching on thermal properties, shrinkage and mechanical properties of poly (lactic acid) films. Journal of Polymers and the Environment, 21, 303-311 (2013). https://doi.org/10.1007/s10924-012-0523-5

[25] Jariyasakoolroj P., Tashiro K., Wang H., Yamamoto H., Chinsirikul W., Kerddonfag N., Chirachanchai S.: Isotropically small crystalline lamellae induced by high biaxial-stretching rate as a key microstructure for supertough polylactide film. Polymer, 68, 234-245 (2015). https://doi.org/10.1016/j.polymer.2015.05.006

[26] Razavi M., Wang S-Q.: Why is crystalline poly(lactic acid) brittle at room temperature? Macromolecules, 52, 5429-5441 (2019).

https://doi.org/10.1021/acs.macromol.9b00595
[27] Ouchiar S., Stoclet G., Cabaret C., Addad A., Gloaguen V.: Effect of biaxial stretching on thermomechanical properties of polylactide based nanocomposites. Polymer, 99, 358-367 (2016).

https://doi.org/10.1016/j.polymer.2016.07.020

[28] Tábi T., Wacha A. F., Hajba S.: Effect of D-lactide content of annealed poly(lactic acid) on its thermal, mechanical, heat deflection temperature, and creep properties. Journal of Applied Polymer Science, 136, 47103/147103/11 (2019).

https://doi.org/10.1002/app.47103

[29] Saeidlou S., Huneault M. A., Li H., Park C. B.: Poly(lactic acid) crystallization. Progress in Polymer Science, 37, 1657-1677 (2012).

https://doi.org/10.1016/j.progpolymsci.2012.07.005

[30] Cole K. C., Depecker C., Jutigny M., Lefebvre J-M., Krawczak P.: Biaxial deformation of polyamide-6: Assessment of orientation by means of infrared trichroism. Polymer Engineering and Science, 44, 231-240 (2004). https://doi.org/10.1002/pen.20022

[31] Sallem-Idrissi N., Miri V., Elkoun S., Krawczak P., Lacrampe M-F., Lefebvre J. M., Seguela R.: Trichroic infrared analysis of the strain-induced structural changes in the PA6 layer of PA6/PE multilayer films under biaxial drawing. Polymer, 50, 5812-5823 (2009).

https://doi.org/10.1016/j.polymer.2009.09.052

[32] Fereydoon M., Tabatabaei S. H., Ajji A.: X-ray and trichroic infrared orientation analyses of uniaxially stretched PA6 and MXD6 nanoclay composite films. Macromolecules, 47, 2384-2395 (2014).

https://doi.org/10.1021/ma402466c

[33] Hutchinson M. H., Dorgan J. R., Knauss D. M., Hait S. B.: Optical properties of polylactides. Journal of Polymers and the Environment, 14, 119-124 (2006). https://doi.org/10.1007/s10924-006-0001-z

[34] Hasan O. A., Boyce M. C.: Energy storage during inelastic deformation of glassy polymers. Polymer, 34, 5085-5092 (1993). https://doi.org/10.1016/0032-3861(93)90252-6

[35] Chandran P., Jabarin S.: Biaxial orientation of poly (ethylene terephthalate). Part II: The strain-hardening parameter. Advances in Polymer Technology, 12, 133-151 (1993). https://doi.org/10.1002/adv.1993.060120203

[36] Gorlier E., Haudin J. M., Billon N.: Strain-induced crystallisation in bulk amorphous PET under uni-axial loading. Polymer, 42, 9541-9549 (2001).

https://doi.org/10.1016/S0032-3861(01)00497-9

[37] Treloar L. R. G.: The physics of rubber elasticity. Oxford University Press, New York (1975).

[38] Sin L. T., Rahmat A. R., Rahman W. A. W. A.: Overview of poly(lactic acid). in 'Handbook of biopolymers and biodegradable plastics: Properties, processing and applications' (ed.: Ebnesajjad S.) Elsevier, Waltham, 1154 (2013). 
[39] Stoclet G., Lefebvre J. M., Séguéla R., Vanmansart C.: In-situ SAXS study of the plastic deformation behavior of polylactide upon cold-drawing. Polymer, 55, 18171828 (2014).

https://doi.org/10.1016/j.polymer.2014.02.010

[40] Sarasua J. R., Arraiza A. L., Balerdi P., Maiza I.: Crystallinity and mechanical properties of optically pure polylactides and their blends. Polymer Engineering and Science, 45, 745-753 (2005).

https://doi.org/10.1002/pen.20331

[41] Terada T., Sawatari C., Chigono T., Matsuo M.: Oriented crystallization of poly(ethylene terephthalate) under uniaxial stretching. Macromolecules, 15, 998-1004 (1982).

https://doi.org/10.1021/ma00232a010

[42] LeBourvellec G., Monnerie L., Jarry J. P.: Amorphous orientation and induced crystallization in uniaxially stretched poly(ethylene terephthalate glycol). Polymer, 27, 856-860 (1986).

https://doi.org/10.1016/0032-3861(86)90294-6

[43] Chang C. L., Chiu W. Y., Hsieh K. H., Ma C-C.: The molecular orientation and mechanical properties of poly (ethylene terephthalate) under uniaxial extension. Journal of Applied Polymer Science, 50, 855-862 (1993). https://doi.org/10.1002/app.1993.070500513
[44] Stoclet G., Seguela R., Lefebvre J-M., Rochas C.: New insights on the strain-induced mesophase of poly $(\mathrm{D}, \mathrm{L}-$ lactide): In situ WAXS and DSC study of the thermomechanical stability. Macromolecules, 43, 7228-7237 (2010). https://doi.org/10.1021/ma101430c

[45] Lee S. C., Han J. I., Heo J. W.: Endotherm just above glass transition in uniaxially drawn poly(lactic acid)s films with various D-isomer contents. Polymer, 54, 3624-3632 (2013). https://doi.org/10.1016/j.polymer.2013.04.063

[46] Oh M. O., Kim S. H.: Conformational development of polylactide films induced by uniaxial drawing. Polymer International, 63, 1247-1253 (2014).

https://doi.org/10.1002/pi.4630

[47] Hu J., Zhang T., Gu M., Chen X., Zhang J.: Spectroscopic analysis on cold drawing-induced PLLA mesophase. Polymer, 53, 4922-4926 (2012). https://doi.org/10.1016/j.polymer.2012.09.012

[48] Wang Y., Liu L., Li M., Cao W., Liu C., Shen C.: Spectroscopic analysis of post drawing relaxation in poly(lactic acid) with oriented mesophase. Polymer Testing, 43, 103-107 (2015). https://doi.org/10.1016/j.polymertesting.2015.03.001

[49] Zhuo R., Zhang Y., Li G., Shao C., Wang Y., Liu C., Cao W., Shen C.: Structural evolution of poly(lactic acid) upon uniaxial stretching investigated by in situ infrared spectroscopy. Vibrational Spectroscopy, 86, 262269 (2016).

https://doi.org/10.1016/j.vibspec.2016.08.001 